\title{
Intra-Annual Studies of Mixed Layer Depth in the Arabian Sea Using A 3 $1 / 2$ Layer Indian Ocean Model
}

\author{
KVKRK Patnaik*, P. Sreenivas, Ch. Venkata Ramu, SVV Arun Kumar and KVSR Prasad
}

Department of Meteorology \& Oceanography, Andhra University, Visakhapatnam, India

\begin{abstract}
Mixed layer is the upper layer of the ocean, where significant physical, chemical and biological activities take place. Knowledge of mixed layer depth variability is important in the studies of air-sea interaction, acoustic propagation, heat transport and fisheries. The Arabian Sea experiences extremes in atmospheric forcing that lead to intra-annual and inter-annual variability. Since the climatic conditions over the Arabian Sea are highly variable, the mixed layer depth also changes seasonally. Hence the intra-annual variability of mixed layer depth in the Arabian Sea has been examined using 3 $1 / 2$ layer Indian Ocean model. The model is integrated for 8 years $(1993-2000)$ with annually varying monthly averaged winds derived from ERS-2 scatterometer. In addition to this data, inter annually varying monthly averaged satellite estimates of precipitation from Global Precipitation Climatology were also incorporated in the model. Model results show a steady deepening of mixed layer depth in the central Arabian Sea during southwest monsoon period. The model shows its capability to predict the shallow mixed layer depths caused by coastal upwelling off Somalia during southwest monsoon period and is able to capture the Lakshadweep high/low as it predicted successfully the deeper/shallow mixed layer observed during these periods.
\end{abstract}

\section{INTRODUCTION}

It has long been realized that Arabian Sea plays an important role in the climate variability of the North Indian Ocean region. Understanding the ocean processes in the Arabian Sea is vital in determining large-scale climate variability of the region. The Arabian Sea experiences extremes in atmospheric forcing that lead to the greatest of the intraannual variability observed in any ocean basin. The wide range of climate variability in the Arabian Sea makes it the only place to look clearly at past climates and possible future climates. There have been numerous studies of the Arabian Sea as scientists were drawn to the interesting and unique features of this monsoon-driven ocean basin. However, most of the focus had been on its unique circulation aspects like the reversing current systems off the Somali and West Indian coasts. But studies on mixed layer are also equally important because it forms the upper layer of the ocean where significant physical, chemical and biological activities take place. It forms the link between the atmosphere and the deeper waters of the ocean and significantly influences the weather and climate in the region. Although considerable work has been done in the past by various workers on the mixed layer dynamics of North Indian Ocean, a complete and systematic study on the MLD of Arabian Sea is still lacking. The main objective of this work is to study the temporal and spatial variability of the mixed layer depth.

Shipboard and moored platform measurements can only sample the ocean at fixed times or locations. A numerical

*Address correspondence to this author at the Department of Meteorology \& Oceanography, Andhra University, Visakhapatnam, India;

E mail: Karakavalasa@yahoo.com model that is adequately verified by in situ measurements can extend, interpolate and extrapolate these measurements in time and space. Moreover model studies can be used to plan in situ measurement strategies to ensure that the relevant features of the ocean are adequately sampled. Because of its seasonal extremes, simulating the Arabian Sea physical processes presents a unique challenge for modelers. Yet significant progress has been made by researchers using a variety of models. Kraus and Turner developed one dimensional mixed layer model based on Kraus-Turner entrainment thermodynamics [1]. Price et al. developed another one dimensional mixed layer model with bulk Richardson number criteria [2].

Several layer models of Indian Ocean circulation are available. Luther and O'Brien, Kindle and Thompson, Perigaud and Delecluse used $1 \frac{1}{2}$ layer model for the study of Indian Ocean dynamics [3-5]. Potema et. al. and Jensen used $3 \frac{1}{2}$ layer model for the investigation of circulation pattern in the Indian Ocean $[6,7]$. Numerous modeling efforts have been made to explain spatial and temporal variability patterns of upwelling/downwilling, mixed layer depth and primary production in the Arabian Sea using reduced gravity ocean circulation models [8-10]. Ryabchenko et al. simulated seasonal variability in physical and biological properties in the northwest Indian Ocean using a sevencompartment biological model coupled to a quasigeostrophic ocean model [11]. Using an one-dimensional model, Wiggert et al. concluded that entrainment driven by convective mixing was an important process during the Northeast monsoon, through its influence on mixed layer [12].

McCreary et al. used an Indian- Ocean ecosystem model of intermediate complexity to study the annual variability of 
physical processes and biological activity in the Arabian Sea. Its physical component is a variable-density 2 1\2-layer model with a mixed layer embedded in layer-1 [13]. McCreary et al. extended the McCreary et al. [13] study to consider the influence of intra-seasonal and diurnal forcing, focusing on a model/data comparison at the Woods Hole Oceanographic Institute (WHOI) mooring site [14]. Shetye examined the annual cycle of mixed layer depth and SST in a zonal strip across the Arabian Sea using Kraus and Turner one dimensional mixed layer model [15].

In the present study an attempt is made to present intraannual variations in mixed layer depth in the Arabian Sea using a $31 / 2$ layer Indian Ocean model. This work deals with the variations of MLD in the Arabian Sea for the period 1993 to 2000.

\section{THE MODEL AND DATA:}

The seasonal variations of mixed layer depth in Arabian Sea are examined using a $3 \frac{1}{2}$ layer Indian Ocean model, forced by ERS-2 Scatterometer derived wind stress. The model is essentially a general circulation model (GCM) of intermediate complexity differing from the sophisticated GCM's in use today in that it has a limited vertical resolution. However the model simplicity is an advantage for computationally efficient and hence easier to isolate basic processes.

The physical model is an active thermodynamic $4 \frac{1}{2}$ layer system that extend throughout the Indian Ocean. However, it is referred to as a $31 / 2$ layer model because $1^{\text {st }}$ and $2^{\text {nd }}$ layers dynamically behave like a single layer with no velocity shear $\left(V_{1}=V_{2}\right)$. The model ocean (Fig. 1) consists of four layers with velocities $\mathrm{Vi}=\left(\mathrm{u}_{\mathrm{i}}, \mathrm{v}_{\mathrm{i}}\right)$, layer thickness $\mathrm{h}_{\mathrm{i}}$, temperature $T_{i}$, and salinity $S_{i}(i=1,2,3$ and 4 is a layer index) overlying a deep inert ocean with temperatures $\mathrm{T}_{\mathrm{d}}=3^{\circ} \mathrm{C}$ and salinity $\mathrm{S}_{\mathrm{d}}=34.8 \mathrm{psu}[14]$.

The layers correspond to distinct oceanic region types, namely the surface mixed layer (layer - 1), the diurnal thermocline (layer - 2), the seasonal thermocline (layer - 3) and the main thermocline (layer - 4). Fluid is allowed to transfer between the layers with velocities $\mathrm{w}_{1}, \mathrm{w}_{2}$ and $\mathrm{w}_{3}$ and the system is thermodynamically active in that, temperature and salinity in each layer is allowed to vary horizontally in response to surface heat and buoyancy fluxes, horizontal advection, entrainment and detrainment. Finally, $h_{1}, h_{2}$ and $h_{3}$ are not allowed to get thinner than prescribed minimum values $h_{1 \min }=10 \mathrm{~m}, h_{2 \min }=1 \mathrm{~m}$, and $h_{3 \min }=10 \mathrm{~m}$. These minima are necessary to keep the model numerically stable. The complete details of the model including the schematic illustration, dynamic and thermodynamic equations, details of entrainment and detrainment etc, as given by Mc Creary [14].

The model was integrated for 8 years (1993 to 2000) with annually varying monthly averaged winds derived from ERS-2 Scatterometer. In addition to the Scatterometer winds, inter-annually varying monthly averaged satellite estimates of precipitation from Global Precipitation Climatology Project were used. These data are available globally on $2.5^{\circ} \mathrm{X}$ $2.5^{\circ}$ latitude -longitude grids [16].

The boundaries for the Arabian Sea shown in this paper differ from the model boundaries. However for showing the original boundary, true map of Arabian Sea was created with the help of Map Viewer (V.5) software and overlaid on to the model plots using Surfer (V.8) software without changing the model grid points. The model was integrated for the eight years to get year wise monthly mixed layer depths in the Arabian Sea. These monthly mixed layer depths were

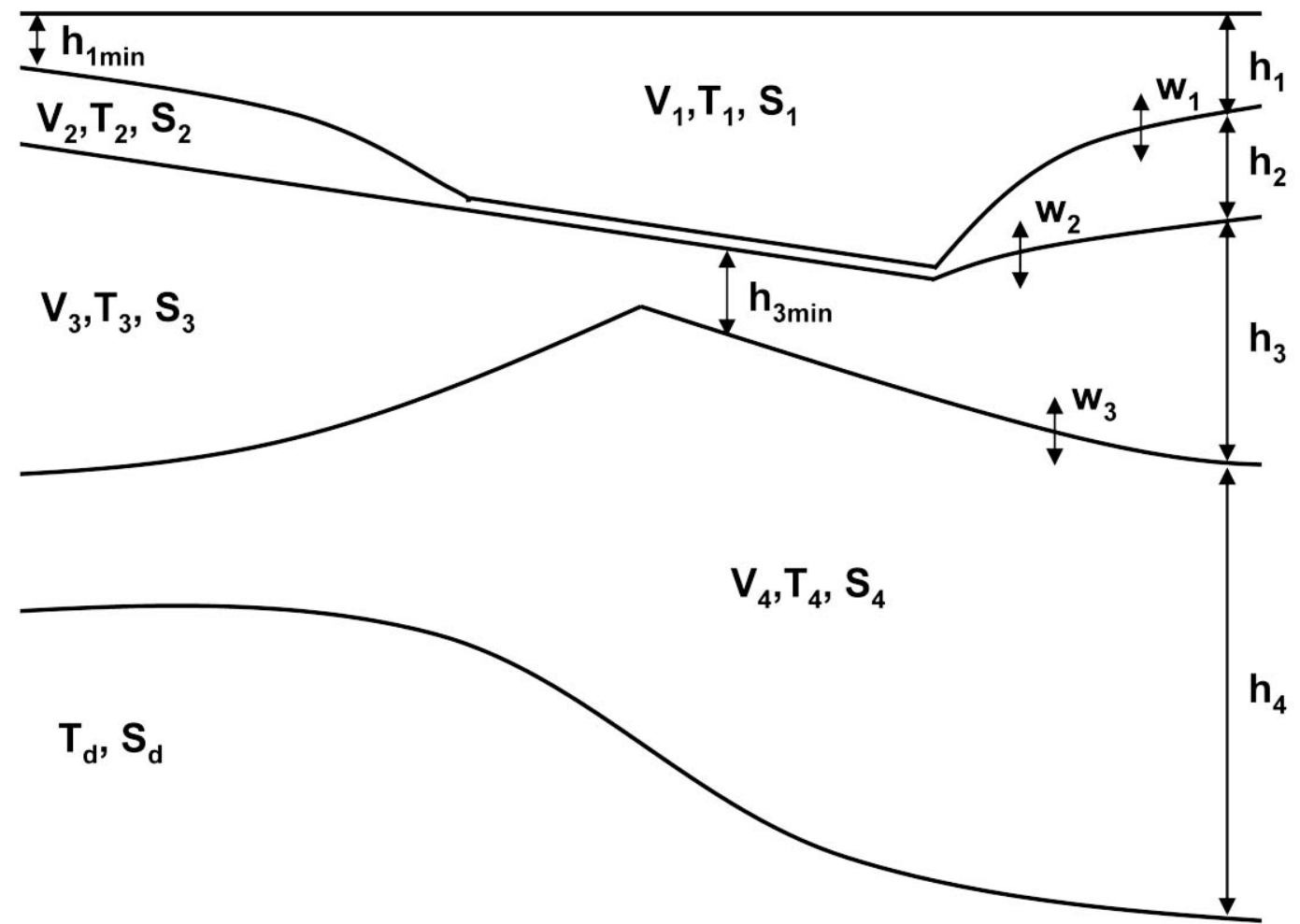

Fig. (1). A schematic diagram showing the model ocean (McCreary et al. 2001). 
averaged to get mean monthly mixed layer variability in the Arabian Sea.

\section{RESULTS AND DISCUSSION:}

\section{Spatial Distribution of Mixed Layer Depth Over Arabian Sea}

Fig. (2) shows spatial distribution of MLD over Arabian Sea for different months as obtained from the model. The model results of the monthly mean MLD over Arabian Sea for the month of January shows deeper mixed layers in the northern as well as central Arabian Sea. Northern Arabian Sea shows nearly 60m MLD, where as central Arabian Sea shows relatively deeper MLD crossing $90 \mathrm{~m}$. The model results show shallow MLD's over eastern Arabian Sea than western Arabian Sea. The model produced relatively deeper MLD's near the southern tip of India, which is due to the Lahshadweep high. In February, the model produced shallow mixed layers through out the basin compared to January. Decrease in the intensity of the Lakshadweep high is observed. In the month of March, the model result shows shallowest MLD of only $15 \mathrm{~m}$. Disappearance of Lakshadweep high is observed. Since the forcing parameters of the model, winds and precipitation are particularly weak during this month the model results in shallow MLD. In April, as in the case of previous month, shallow mixed layers throughout the Arabian Sea are noticed. A closed contour pattern in the MLD distribution with values increasing towards center is noticed. Maximum MLD of $45 \mathrm{~m}$ is found in the central Arabian Sea where as eastern and southern Arabian Sea show MLD of about $30 \mathrm{~m}$. In May the western Arabian Sea shows MLD greater than $50 \mathrm{~m}$, while the remaining parts of the Arabian Sea have MLD of about $30 \mathrm{~m}$.

$\mathrm{n}$ June, with the onset of summer monsoon, the model gives deep Mixed Layers (75m) in the central as well as in the south western Arabian Sea. Along the coast of Somalia, the model captures the coastal upwelling and shows shallow Mixed Layer. Shallow MLD's are also seen around the southern tip of India in the model results, which is due to the Lakshadweep Low. On the whole Southeast Arabian Sea experiences relatively shallow MLD ranging from 30 to $45 \mathrm{~m}$. In July the model shows further deepening of MLD in central Arabian Sea which extended northeast. In the Western Arabian Sea again along Somalia Shallow MLD's are seen due to the continuing upwelling in the region. The model picks up the Lakshadweep Low around the southern tip of India and predicts shallow MLD in the region. Along the coastal belt of Arabian Sea, a closely packed contour pattern parallel to the coast is noticed which indicates sudden decrease in MLD towards the coastal areas.

In August MLD distribution is similar to that of the previous month, but with decreased depths. The central Arabian Sea shows a closed circular system of MLD contours with a maximum MLD of about $60 \mathrm{~m}$ at the center. From central Arabian Sea MLD gradually decreased outwards. During September and October shallow MLDs of about 15 -30m are observed throughout the Arabian Sea. The weakening of SW monsoon winds leads to shallowest MLDs during this month. Disappearance of Lakshadweep Low and coastal upwelling off Somalia are also noticed. In November northeasterly winds appear in the Arabian Sea marking the beginning of the northeast monsoon causing relatively deep mixed
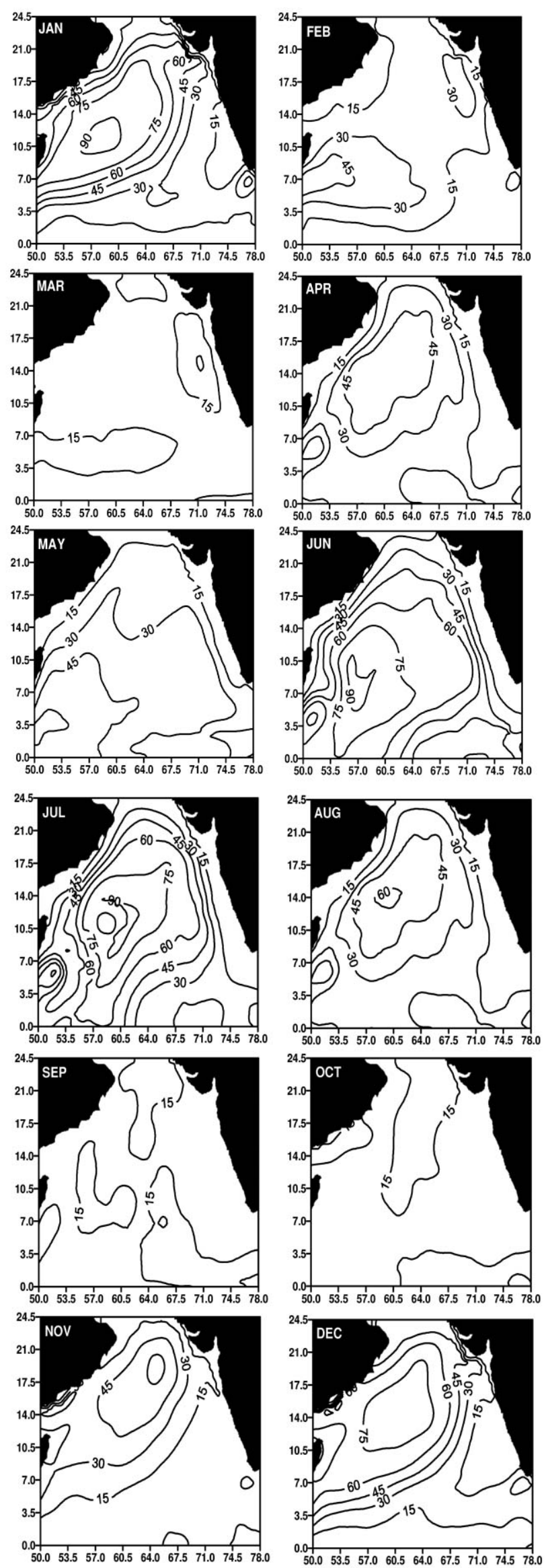

Fig. (2). Monthly mean MLD as estimated from $3 \quad 1 / 2$ layer IO model for the months January to December. 
layer (around 60m) over the northern Arabian Sea. Remaining parts of the Arabian Sea show shallow Mixed Layer Depths. A small pool of relatively high MLD $(30 \mathrm{~m})$ is observed near southern tip of India related to the development of Lakshadweep High.

In December, the model results show deeper MLDs exceeding $75 \mathrm{~m}$ in the northern and central Arabian Sea in response to the northeast monsoon winds. The model captured the shallow mixed layer conditions $(<30 \mathrm{~m})$ over southern Arabian Sea.

Intra-Annual Variability of Mixed Layer Depth in the Arabian Sea

In response to the reversing monsoonal winds, the physical processes in the Arabian Sea are subjected to remarkable intra-annual (monthly) variations. Some of these include reversal of the current off Somali coast, significant seasonal variations in the sea surface temperatures and occurrence of up-welling and down-welling in response to the changing wind fields. All these processes to some extent affect the mixed layer dynamics and as a result different regions of the Arabian Sea show different variability patterns. In this section, intra-annual variations of mixed layer depth in the Arabian Sea as obtained from the model study are discussed in detail.

To study the intra-annual variations of MLD in the Arabian Sea, the entire basin is divided into four separate regions namely southwest Arabian Sea, southeast Arabian Sea, central Arabian Sea and northern Arabian Sea as shown in Fig. (3). Then the MLD values for all the grids falling in each region are averaged in order to get the monthly averages of each region. Particular care has been taken to remove the values of the coastal grids while averaging to avoid any possible errors. The monthly average values for each region are plotted in Fig. (4) to study the region-wise intra- annual variability of MLD in the Arabian Sea.

Fig. (4) shows deeper mixed layers of about 65 to $75 \mathrm{~m}$ in the northern Arabian Sea during the period November to January; while this winter deepening started from December and sustained up to January in the case of central Arabian Sea. In the southwest Arabian Sea and in the southeast Arabian Sea, shallow MLD of about 20 to $30 \mathrm{~m}$ is observed during this period. From February to May mixed layer depth shows a decreasing trend attaining shallowest values in the month of March for all the four regions of the Arabian Sea. Once again during June to August mixed layer depth shows higher values in the southwest and central Arabian Sea attaining deepest values $(90 \mathrm{~m})$ in July. At the same time northern Arabian Sea shows moderate deepening of MLD while southeast Arabian Sea shows still shallow MLD up to $30 \mathrm{~m}$ only. In August decreasing trend in mixed layer depth is observed in the four regions of the Arabian Sea. During September and October mixed layer depths once again shoal to minimum values in all parts of Arabian Sea.

On the whole almost similar seasonal and monthly variations in MLD are observed for all regions. Out of the four regions, southeast Arabian Sea exhibits minimum annual MLD variations with a range of only $20 \mathrm{~m}$. Compared to other regions, this region has very shallow mixed layer depths throughout the year. Southwest Arabian Sea exhibits maximum annual variations in MLD with a maximum of $80 \mathrm{~m}$ occurring in June and a minimum of $15 \mathrm{~m}$ occurring in October. It is observed that northeast monsoon does not have much effect on this part of Arabian Sea.

The central Arabian Sea and northern Arabian Sea show

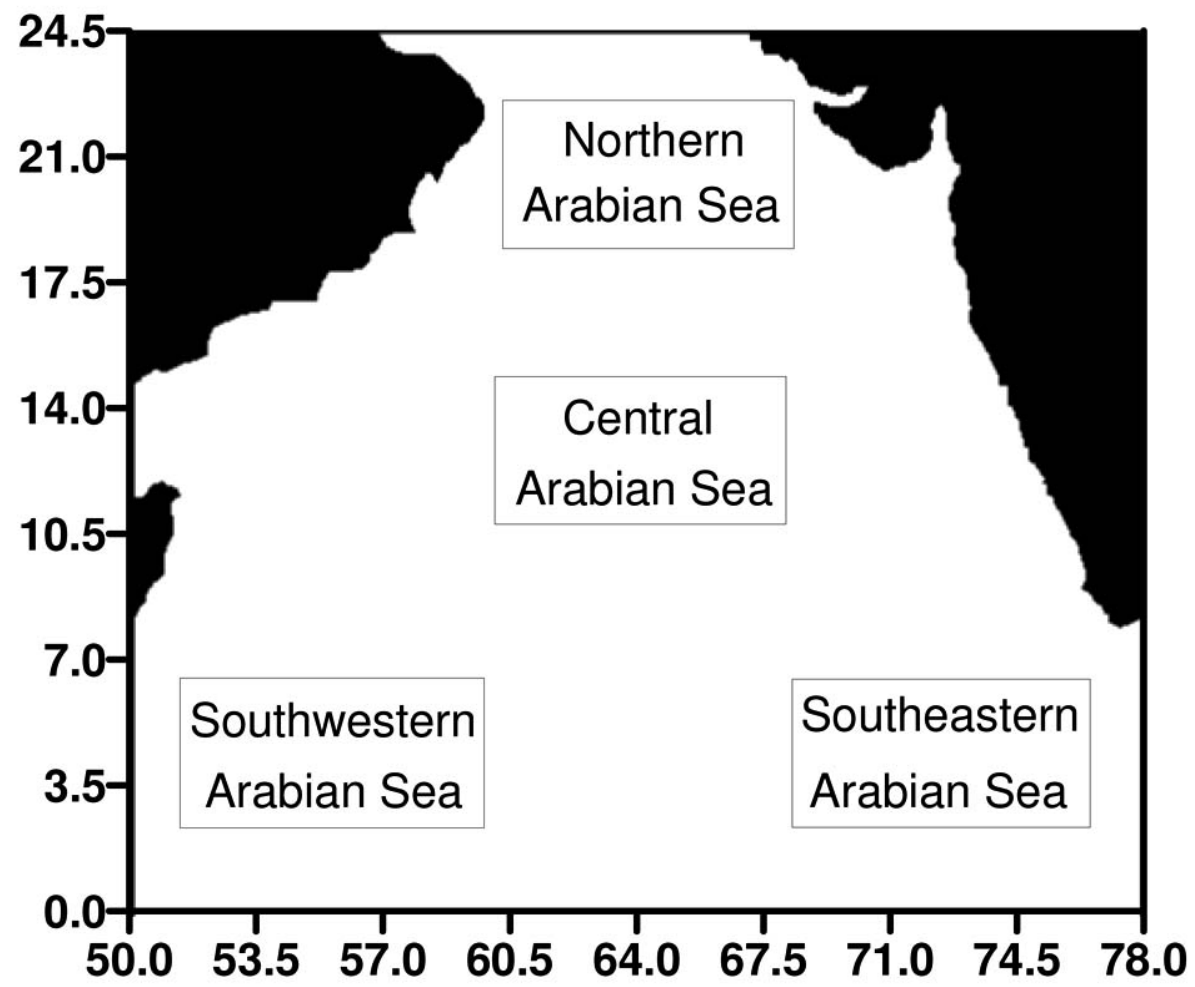

Fig. (3). Map showing division of Arabian Sea into 4 regions. 


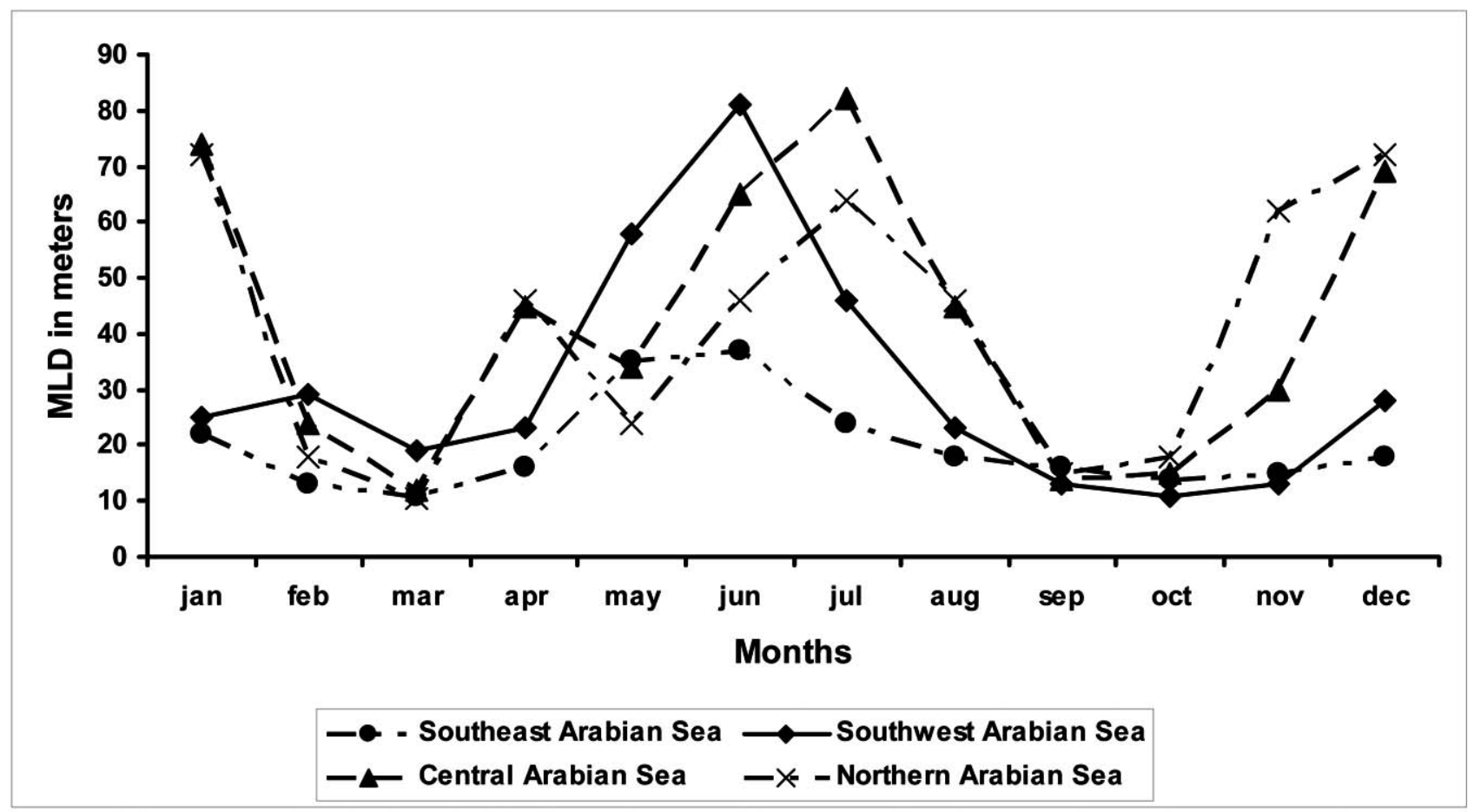

Fig. (4). Intra-annual variability of MLD over the Arabian Sea.

more or less similar intra-annual variations in MLD. These two regions are affected fairly well by both monsoons i.e. southwest as well as northeast monsoon. As shown in Fig. (4) two phases of mixed layer deepening occur, one in July and the other in December corresponding to the two monsoons. The central Arabian Sea shows almost equal MLD peaks, where as for northern Arabian Sea the MLD peak corresponding to the northeast monsoon is dominant.

It is observed that although the entire Arabian Sea is viewed as a single basin, there are considerable deviations in the mixed layer dynamics when viewed as different regions. As shown in Fig. (4), northeast monsoon induces deep MLD only in northern and central Arabian Sea while in the Southern Arabian sea the MLD is not affected much by northeast monsoon.

\section{SUMMARY}

The seasonal variations of mixed layer depth in Arabian Sea have been examined using $31 / 2$ layer Indian Ocean model. From this study it is found that MLD shallows considerably towards coastal boundaries and towards equator. Maximum variance in the mixed layer depth is observed in the northern and central Arabia Sea. Model results show a steady deepening of mixed layer depth in the central Arabian Sea during southwest monsoon period. From the monthly distribution of mixed layer depth as obtained from the model, it is found that the model performance is better in both monsoon periods while during transition periods (March, September and October) the MLD values are somewhat underestimated by the model. The model shows its capability to predict the shallow mixed layer depths caused by coastal up welling off Somalia during southwest monsoon period. The model is able to capture the Lahshadweep high/ low as it predicted successfully the deeper/shallow MLDs observed during these periods. Study of intra-annual variability of MLD over Arabian Sea reveals that out of the four regions, southeast Arabian Sea exhibits minimum annual MLD variations with a range of only $20 \mathrm{~m}$. Compared to other regions, this region has very shallow mixed layer depths throughout the year. Southwest Arabian Sea exhibits maximum annual variations in MLD with a maximum of $80 \mathrm{~m}$ occurring in June and a minimum of $15 \mathrm{~m}$ occurring in October. It is observed that northeast monsoon does not have much effect on this part of Arabian Sea. The central Arabian Sea and northern Arabian Sea show more or less similar intra-annual variations in MLD. These two regions are affected fairly well by both monsoons.

\section{ACKNOWLEDGEMENTS:}

The authors gratefully acknowledge Prof. BSR Reddy, Department of Meteorology \& Oceanography, Andhra University, Visakhapatnam for his constant support and encouragement. The authors wishes to acknowledge the support received from Dr. Rashmi Sharma, Dr. Sujit Basu and Dr. V.K. Agarwal, Meteorology \& Oceanography group, Space applications centre (SAC), Ahmedabad. The authors thankfully acknowledge the financial support extended by ISRORESPOND, Bangalore.

\section{REFERENCES}

[1] Kraus EB, Turner JS. A one-dimensional model of the seasonal thermocline, II: the general theory and its consequences. Tellus 1967; 119: 98-106

[2] Price JF, Weller RA, Pinkel R. Diurnal cycling: observations and models of the upper ocean response to diurnal heating, cooling and wind mixing. J Geophys Res 1986; 91: 8411-27. 
[3] Luther ME, O'Brien JJ. A model of seasonal circulation in the Arabian Sea forced by observed winds. Prog Oceanogr 1985; 14 : 353-85.

[4] Kindle JC, Thompson JD. The 26 and 50 day oscillations in the western Indian Ocean: model results. J Geophys Res 1989; 94: 4721-36.

[5] Perigaud C, Delecluse P. Simulations of dynamic topography in the northwestern Indian Ocean with input of SEASAT altimeter and Scatterometer. Ocean-Air Interactions 1989; 1: 289-309.

[6] Potemra JT, Luther ME, O'Brien JJ. The seasonal circulation of the upper ocean in the Bay of Bengal. J Geophys Res 1991; 96(C7): 667-12, 683

[7] Jensen TG. Modelling the seasonal undercurrents in the Somali current system. J Geophys Res 1991; 96: 22: 22151-67.

[8] Luther ME, O'Brien JJ, Prell WL. Variability in upwelling fields in the north-western Indian Ocean over the past 18,000 years; 1, Model experiments. Paleoceanography 1990; 5: 433-45.

[9] Prell WL, Marvil RE, Luther ME. Variability in upwelling fields in the northwestern Indian Ocean over the past 18,000 years; 2, Data -model comparison at 9000 years B.P. Paleoceanography 1990; 5: 447-57.
[10] Brock JC, McClain CR, Luther ME, Hay WW. The phytoplankton bloom in the northwest Arabian Sea during the southwest monsoon of 1979. J Geophys Res 1991; 96(c11): 20,623-642.

[11] Ryabchenko VA, Gorchakov VA, Fasham MJR. Seasonal dynamics and biological productivity in the Arabian Sea euphotic zone as simulated by a threedimensional ecosystem model. Global Biogeochem Cycles 1998; 7: 417-50.

[12] Wiggert JD, Jones BH, Dickey TD, et al. The Northeast Monsoon's impact on mixing, phytoplankton biomass and nutrient cycling in the Arabian Sea. Deep Sea Res part II Top Stud Oceanogr 2000; 47: 1353-85.

[13] Mc Creary JP, Jr Kohler KE, Hood RR, Olson DB. A fourcomponent ecosystem model of biological activity in the Arabian Sea. Prog Oceanogr 1996; 37: 193-240.

[14] Mc Creary JP, Jr Kohler KE, Hood RR et al. Influences of diurnal and intra-seasonal forcing on mixed-layer and biological variability in the Arabian Sea. J Geophys Res 2001; 106: 7139-55.

[15] Shetye SR. model study of the seasonal cycle of the Arabian Sea Surface Temperature. J Mar Res 1986; 44: 521-42.

[16] Huffman G J, Adler RF, Morrissey MM, et al. Global precipitation at one-degree daily resolution from multi-satellite observations. J Hydrometeorol 2001; 2: 36-50.

(C) Patnaik et al.; Licensee Bentham Open.

This is an open access article licensed under the terms of the Creative Commons Attribution Non-Commercial License (http://creativecommons.org/licenses/ by-nc/3.0/) which permits unrestricted, non-commercial use, distribution and reproduction in any medium, provided the work is properly cited. 